ORIGINAL ARTICLE

\title{
Critical Media Industry Studies: A Research Approach
}

\author{
Timothy Havens ${ }^{1}$, Amanda D. Lotz ${ }^{2}$, \& Serra Tinic ${ }^{3}$ \\ 1 Department of Communication Studies and African American Studies Program, The University of lowa, lowa \\ City, IA 52242-1498 \\ 2 Department of Communication Studies, University of Michigan, Ann Arbor, Ml 48104-2523 \\ 3 Media Studies, Department of Sociology, University of Alberta, Edmonton, AB T6G 2H4
}

\begin{abstract}
This article identifies the primary features of what we term "critical media industry studies," emphasizing midlevel fieldwork in examining media industries and delimiting new ways of understanding, conceiving, and studying media industries from a critical perspective. We provide a general framework for the nascent yet growing body of work that locates industry researh on particular organizations, agents, and practices within vast media conglomerates operating at a global level. We mark out the most general boundaries of such an endeavor by synthesizing the extant research in critical media industry studies, the ways in which concepts and methods of cultural studies have been adapted to the study of industry practices, and address the main gaps and trajectories of such research.
\end{abstract}

doi:10.1111/j.1753-9137.2009.01037.x

\section{Critical media industry studies: Reclaiming a research agenda}

If the ways that we have traditionally studied the media can be categorized into general areas of industry, text, and audience, then the vast majority of critical media scholarship has favored the latter two areas. This is not to say that researchers in a variety of other disciplines including sociology, mainstream economics, and political economy have not produced important insights into the operations of the media industries and the ways in which economic, regulatory, and institutional forces influence cultural output. Indeed, the majority of critical research into the media industries has been conducted from a political-economic perspective that emphasizes macrolevel structural issues of regulatory regimes, concentration of media ownership, historical change, and their larger connection to capital interests. We, however, believe that another tradition of critical media industry study — emphasizing

Corresponding author: Amanda D. Lotz; e-mail: lotz@umich.edu Authors' names are listed alphabetically to reflect their equal contributions to this paper 
more microlevel industrial practices - can be found in the history of critical cultural media studies. The purpose of this article is to identify the primary features of what we term "critical media industry studies" and to distinguish such research from other forms of industry analysis, particularly macrolevel political economy. Our objective is to propose a general framework for examining media industries that we believe can bring important new ways of understanding, conceiving, and studying the media industries from a critical perspective.

Each of us comes to the study of media industries from training in critical cultural studies, which emphasizes the complex interplay of economic and cultural forces, as well as the forms of struggle and compliance that take place throughout society at large and within the media industries in particular. While we admit that the terrain of "cultural studies" may now be so complicated and contested as to make our decision to locate ourselves within its intellectual scope confusing, we mean to signal with it our attention to the complex and ambivalent operations of power as exercised through the struggle for hegemony. Moreover, we disagree with Murdock and Golding's (2005) assertion that "literary and art historical studies" represent the core of cultural studies (p. 61). As we will elaborate, we find much of value in the foundational scholarship in cultural studies and particularly the Birmingham School's early debates regarding the sociocultural role of the media. Although the emphasis on power and ideology may have diminished in some areas of cultural studies scholarship over the past few decades, these processes remain central tenets with which we can better understand the complex processes at work within the media as meaning-making institutions. In brief, we argue that the time has come to revisit the theoretical and methodological terrain that generated a more critically informed media studies paradigm.

It is perhaps predictable that the study of the media as industry should take on a more prominent role in cultural studies research at this particular historical juncture. As digitalization and globalization have been transforming our relationships with media, as well as the quantity, quality, and diversity of mediated texts themselves, industrial practices have moved closer to the center of our understanding of contemporary media phenomena. Yet years of neglecting issues that originate at the intersection of industry and culture have led to some uncertainty about how to integrate industrial processes into the study of cultural processes, with the result that theories and assumptions about industrial practices from other paradigms are often "shoehorned" into contemporary analyses. In particular, critical political economy approaches, which predominantly and consistently focus on the larger level operations of media institutions - and, with few exceptions, emphasize news production - have been a favored paradigm among many media scholars looking to add an industrial dimension to their research. Our purpose in this paper is not to reopen debates between political economists and cultural studies scholars, nor to argue for the superiority of our critical media industry studies framework. Like critical political economists, we are concerned with the "pivotal role" that media institutions play in "organizing the images and discourses through which people make sense of the world" (Murdock \& Golding, 2005, p. 60). However, we are primarily interested 
in the production of entertainment programming, thus limiting the usefulness of many political-economic theories and perspectives, which are based on the industrial analysis of news. In addition, the models of power and of society, which support much of political economy research, do not sit comfortably alongside the models that most cultural studies scholars work from and that we believe continue to prove valuable.

The limitation we find with critical political economy approaches to the media industries results from their consistent focus on the larger level operations of media institutions, general inattention to entertainment programming, and incomplete explanation of the role of human agents (other than those at the pinnacle of conglomerate hierarchies) in interpreting, focusing, and redirecting economic forces that provide for complexity and contradiction within media industries. Overall, there is a general neglect of quotidian practices and competing goals, which are not subject to direct and regular oversight by corporate owners, and which define the experiences of those who work within the industry. Similarly, if and when popular culture is considered within a political-economic analysis, there is a reductionist tendency to treat it as yet another form of commodified culture operating only according to the interests of capital. There is little room to consider the moments of creativity and struggles over representational practices from that vantage point. That said, similar to political economy, and in contrast to other forms of media industry analysis, we are fundamentally concerned with questions of power; although we perhaps draw from a different range of thinkers in order to explain what we identify as the "complex, ambivalent, and contested" behavior noted by Hesmondhalgh (2002, p. 3), which occurs in these industries.

Consequently, our aim here is to offer a general framework for the nascent yet growing body of work that locates industry research on particular organizations, agents, and practices within what have become vast media conglomerates operating at a global level. We do not intend to provide a totalizing or restrictive model for such research but, rather, we mark out the most general boundaries of such an endeavor. Herein, we synthesize the extant research in critical media industry studies, the ways in which concepts and methods of cultural studies have been adapted to the study of industry practices, and address what we see as the main gaps and trajectories of such research. In recent years, we have noted a wide range of work that often hints at offering this contribution. Typically, due to the absence of a shared conceptual grounding, this work sets forth theories and assumptions appropriate particularly to the study at hand with an increasing and problematic array of monikers for this work including: critical production studies (Caldwell, 2008), creative industry studies (Hartley, 2005), cultural economy (du Gay \& Pryke, 2002), the circuit of cultural production (du Gay, 1997), and middle-range theory (Cunningham \& Jacka, 1996), among others. We hope that such a review and synthesis will help stabilize critical media industry studies as a coherent component within projects at the intersection of cultural studies and media studies, and that such approaches might one day become as synonymous with cultural studies as are the practices of textual and reception analysis. 
The framework we outline here emphasizes midlevel fieldwork in industry analyses, which accounts for the complex interactions among cultural and economic forces, and is drawn from our review of media industry scholarship as well as our own research. Culture comes into our considerations in two ways: First, in an anthropological sense, critical media industry studies examines the business culture of the media industries; how knowledge about texts, audiences, and the industry form, circulate, and change; and how they influence textual and industrial practices. Second, in an aesthetic sense, critical media industry studies seeks to understand how particular media texts arise from and reshape midlevel industrial practices. In exploring these issues, critical media industry studies adopts an understanding of power derived from Foucault (1979) and Gramsci (1971). Rather than envisioning power as a form of economic control over media organizations and laborers, we understand it as "productive" in the sense that it produces specific ways of conceptualizing audiences, texts, and economics. Also, rather than being exercised through the coercive practices of media moguls, we see power as a form of leadership constructed through discourse that privileges specific ways of understanding the media and their place in people's lives.

Despite our critiques of how critical political economy has been predominantly operationalized, we do not seek to displace that framework. Rather, we seek a conversation about the future and how these approaches might better complement each other in their pursuit of answers to similar questions and in creating generative rather than antagonistic discussions about their differences. We seek to establish a place at the metaphorical table and to cull together the growing array of critical interventions into the study of media industries into a definable entity so that we might stop defining ourselves by what we are not.

\section{Traditions of media industry scholarship}

As already noted, political economy has traditionally dominated intellectual consideration of the media industries. Akin to the situation of cultural studies, this paradigm has also become considerably broad with a variety of subapproaches, based largely upon differing interpretations and adaptations of Marxist theory. As scholars writing in the North American context, we most often encounter versions of political economy derived from the work of Herbert Schiller (1989) and Dallas Smythe (1981), whose approaches have been reproduced by generations of academics who maintain an unreconstructed Marxist theoretical framework. As David Hesmondhalgh (2006, 217) asserts, "the mainstream tradition of Marxian political economy of culture in the U.S.A" begins from the assumption that media culture is the ideological extension of powerful capitalist forces and that the role of research is consequently to uncover the ways in which we, as citizen-audiences, are socialized into broader economic interests. Traces of the Frankfurt School's conceptualization of the media as agents of false consciousness remain implicitly woven throughout the arguments of American political economy scholars. We are not completely at odds with the 
Marxist foundation of this perspective. However, we underline that Marx, himself, argued that capitalism is an inherently contradictory system. It is the inability, or perhaps reluctance, to acknowledge how these contradictions account for instances of creativity, resistance, and change that we find difficult to reconcile within the American paradigm. We cannot accommodate the conclusion that meaning, textual production, and industry practices are predictable or guaranteed to reflect only the interests of those who control the means of production.

In this regard, we have long found far more in common with the tradition of political economy developed predominantly by scholars working in the UK and continental Europe (see, for example, Miege, 1989). In what is arguably the most concise and recent delimitation of critical political economy, Murdock and Golding (2005) insist that the cultural industries are important objects of study because "telecommunications and computer networks provide the essential infrastructure that allows businesses to coordinate activities," because "as the major arena for advertising, the commercial media play a pivotal role in matching consumer demands to production," and because "media corporations are significant economic actors" (p. 60). This acknowledgment that economic factors must be connected to complex practices that produce a field of images and discourses resonates most consistently with the central assumptions of critical media industry studies.

We diverge to the degree that critical media industry studies is also concerned with the "micropolitics of everyday meaning making," which most political economists dismiss as less significant than structural issues (Murdock \& Golding, 2005, p. 61). However, rather than centering those micropolitics within acts such as the resistive readings of individual audience members - as is often the caricature of cultural studies-critical media industry studies examines the micropolitics of institutional operation and production practices. Here we are in accord with Garnham's (2005) reflexive critique of political economy to the extent that, although it can provide descriptions of "broad patterns of cultural output, distribution and consumption," it

can tell us very little directly about content. This requires, in my view, a detailed analysis of the production process and a focus on cultural producers as a status or class group, on the labour process, and on the relationship between producers and consumers. In so far as culture can be said to be ideological, this is mediated through the ways in which the intentions of producers, and the desires and needs of consumers, are themselves molded by the wider capitalist social formation. It is also the case, I think, that both the intentions of producers and the desires and needs of consumers in the cultural field are determined at a deeper human level and move to much longer historical rhythms than can be captured by the capitalist mode of production (p. 486, emphasis added).

With perhaps some slight variation in theorizing the relations of production, we believe that critical media industry studies fills the niche that Garnham so aptly describes. 
Studies of the operation of power within complex media industries provide valuable information about how workers function, which is not illuminated by conventional critical political economy research. The variation between these approaches might be compared to the difference in terrain detail evident in flying over a city in a helicopter instead of a jet plane. The "jet plane" vision offers a more expansive view, but many details are obscured. The "helicopter" view allows us much finer detail, albeit with narrower scope. As per this metaphor, the view of industrial practices and approach to the operations of power particular to critical media industry studies informs us of the complexity and contradiction of power relations that are often obscured at jet-plane heights. For example, Havens (2006) shows through an examination of the process of global television trade that most channels around the world retain local decision-making control over foreign imports, even channels such as HBO Central Europe that offer localized versions of U.S. channels. This observation stands in stark contrast to the expectations of political economists, who suggest that U.S.-owned channels in foreign markets serve as mere pipelines for their parent companies' programming (Herman \& McChesney, 1997, pp. 68-69). In fact, this kind of forced purchase is rare as each channel is expected to turn a profit and therefore needs to respond to local competitive and cultural environments. Instead, the influence of U.S.-based media conglomerates on such channels is more subtle and profound, and is exercised through leadership, particularly "best practices" and the training of foreign professionals, which influences television programmers around the world to think of the medium, its textual pleasures, and its possibilities in similar ways.

In another case, Lotz's (2007) research of the process of advertising buying in the U.S. television industry revealed the meaningful intricacies in the allocation of commercial funding. This process is far more nuanced than simple explanations of the role of advertiser influence on textual output had accounted for. Through interviews with media buyers and observation of the "upfront" process in which $70 \%-90 \%$ of advertising for the coming year is purchased, Lotz identified the detailed practices and complex interpersonal dynamics that scholars have not considered in advancing assessments of the all-powerful role of advertisers as determiners of commercial popular culture. Again, our purpose here is not to privilege the information gained from the helicopter view, but to acknowledge growing evidence of the disparate perspectives evident at each level and the need to expand explanations of the operations of these industries to better encompass both levels of analysis.

A second common type of media industry analysis is found predominantly in sociology and is often characterized in terms of the "production of culture" model. This approach emphasizes "how the symbolic elements of culture are shaped by the systems within which they are created, distributed, evaluated, taught, and preserved" (Peterson \& Anand, 2004, p. 311). Richard A. Peterson (1982), a key contributor to this tradition, proposed six facets of production that are analyzed within this paradigm: technology, law and regulation, industry structure, organization structure, occupational careers, and market. Such studies approach cultural industries with a 
focus on common organizational issues and ultimately conceive of cultural industries with little distinction from any other industry.

In contrast to critical media industry studies, the production of culture model tends to be focused on organizational relations and the ways in which practices and processes yield specific outcomes, with little explicit articulation of power at either a macro- or microlevel. Methodologically, the production of culture approach operates at what we term the "helicopter" level; however, it does not employ anything approaching the level of critical analysis of its observations that characterizes the perspective of critical media industry studies. In a detailed review article, Peterson and Anand (2004) identify many of the key critiques of the production of culture approach, including the fact that it ignores those characteristics that make art and culture distinct from other industries, pays little attention to the role of fans and consumers, does not examine the meaning of cultural productions, and, as mentioned, attends minimally to the operation of power (pp.326-327). In the end, it presents a functionalist explanation of cultural production along the lines of assembly line manufacturing. These critiques present major stumbling points for critical media scholars for whom such features are central to basic conceptualizations of media operations. Although the review of literature presented by Peterson and Anand asserts evidence of the production of culture perspective in an exceptionally broad array of scholarship, many of the authors noted employ a far more critical perspective than is common in the production of culture approach.

A third approach is found in Joseph Turow's (1997) "power roles" framework, which offers an alternative model of power than those found in both political economy and production of culture studies. Turow uses a rudimentary but productive conceptualization of power as "the use of resources by one organization to gain compliance by another organization" (p. 24). He enumerates a wide array of power roles, moving beyond the regulators and financiers that figure prominently in political economic approaches to integrate the actions of the vast staffs involved in every aspect of the production and circulation of media as well as the audience and public. Turow consequently acknowledges the power sharing and cooperation that is necessary for these industries to accomplish their tasks - the processes likewise emphasized by the production of culture approach. The variability and lack of centrality characteristic of his organization of media industries provide a theoretical framework with which the contradictory actions of a conglomerate or the creation of unconventional programming might be explained.

Despite these strengths relative to other models, Turow's power role perspective lacks the theoretical tools to explain and explore the role human agents play in the industry, instead conceiving of them primarily as extensions of institutional interests. His analysis does, however, provide a much stronger theoretical basis for addressing the complicated and varied division of duties central to critical media industries studies.

Other paradigms warrant brief mention and are perhaps best differentiated by their particular conceptions of how culture works. Various mainstream media 
economists and management scholars such as David Waterman (2005) and Bruce Owen and Steven Wildman (1992) argue that commercial media give people what they want. This supply-demand thesis equates free markets with unlimited free choice and thus sees the role of research as one that helps the media operate more effectively. This set of assumptions leads to more descriptive than critical business analysis, and also has been distinguished as "administrative" research.

Also, what we call liberal-pluralist scholarship allows for the possibility that prosocial culture can be created by commercial media and that a "free marketplace of ideas" can be achieved provided governmental oversight introduces ideal market conditions in order to stem the excesses of media corporations that tend to subvert the market. Such scholars are willing to accept a regulated commercial media (unlike U.S. Marxian political economists such as McChesney), although they tend not to engage in sophisticated empirical analysis of functioning media industries. These scholars are certainly "critical" of practices such as conglomeration, but their massive lists of who owns what assume ownership is determinant of practice and tell us little about how these companies operate or of the complex practices and negotiations located within and among their many divisions. Ben Bagdikian (2004), for instance, claims that under ideal competitive conditions, commercial media would provide "differing kinds of programs that reflect the widely different tastes, backgrounds, and activities of the American population" (p. 6). This perspective is also reflected in the texts on media industries of David Croteau and William Hoynes (2006); and like much political economy work, news is the overwhelming form of media to which this research attends.

\section{Antecedents of a critical media industry studies approach: Influences and counterpoints}

As our overview thus far indicates, we are not attempting to revolutionize the study of the media industries. In fact, our project is best viewed as a recuperation of an earlier cultural studies project that was fundamentally concerned with the material impact of cultural production. This aspect of critical media industry studies can be traced to debates between culturalism and structuralism in the early years of the development of cultural studies. The work of Raymond Williams (1958/1983), a member of the "culturalist" contingent, is particularly germane to our discussion. Williams' cultural materialism thesis provided a compelling critique of the Marxist overdetermination of the base (economy) as the predominant force in its mastery over superstructure (cultural and political institutions). His argument that base and superstructure exist in a dialectical relationship in which "materially produced symbolic goods" contribute to the systems of cultural meaning in industrialized societies remains salient in contemporary analyses of the cultural industries (Stevenson, 2002, pp. 15-16). Interestingly, Williams is one of the few scholars whose work has had a profound influence on both cultural studies and political economy approaches to media studies, as evidenced in the works of Stuart Hall (1983) and Nicholas Garnham (2005), and strains of which can be gleaned in Richard Johnson's (1986/1987) early circuit model 
of media culture. Hall's work is especially instructive to our proposed framework. Although he recognized the importance of Williams' theoretical contributions, he rightly critiqued the culturalist tendency to privilege the domain of lived experience and consciousness as the defining aspect of sociocultural life. The lack of emphasis given to determining conditions led to his willingness to engage with structuralist debates on the centrality of ideology (pp. 26-27). Hall's refusal, however, to reduce lived experience solely to the classifications and categories of ideological structures would have profound significance on an early generation of media scholarship. His incorporation of Gramsci's theorization of the ideological struggle for cultural hegemony and Foucault's emphasis on the fluidity of determination, (with a cautious eye to Foucault's tendency "to suspend judgment about any form of relationship between determining practices"), provides the bridge between these paradigms that we see as being of paramount importance to critical media industry studies (pp. 33-36). Consequently, cultural studies' early conceptualization of the media as symbol-generating, ideological, and economic institutions serves as one of the touchstones we invoke in our call for a return to foundational materialist concerns in critical cultural research of industrial processes.

Some of the earliest works that influence our concept of critical media industry studies appeared subsequent to and coterminous with these initial theoretical incursions of media industries research within cultural studies-although most bore little explicit indication of the work of Williams, Hall, or Johnson. Many of the scholars researching the practices of media industries first emerged from sociology or were otherwise ambiguously placed in terms of academic disciplines. For example, Todd Gitlin's (1983) account of the complex operations and negotiations behind the scenes of the U.S. television industry was informed by extensive interviews with industry workers. Similarly, in addition to his power-role framework, Turow also published numerous empirical, theoretical, and methodological interventions into the study of industry (see, for example Turow, 1981, 1990). His (1981) explorations of the industrial and organizational factors that enable the production of unconventional television embody many of the tenets and assumptions of cultural studies without explicitly drawing from it.

The works of Williams, Hall, and Johnson also influenced the first wave of American cultural and media studies research that addressed aspects of media production in a manner distinct from the more dominant political economy approaches of the time. A key turning point occurred as many among the initial generation of U.S. cultural and media studies scholars began to publish their first books. Several of these volumes - initially written as dissertation research in the late 1980s - provided sophisticated syntheses of the sociohistorical and institutional conditions that structured the production of particular television texts and genres (see, for example, Anderson, 1994; Boddy, 1990; Curtin, 1995). Julie D’Acci's (1994) Defining Women: The Case of Cagney and Lacey (1994) is perhaps one of the most important and yet underconsidered examples of cultural studies approaches to media industry research and one which we see as an influential predecessor to a critical media 
industry studies approach. D’Acci's extensive interviews and observations throughout the production process of the television series illustrated the ways in which producers attempted to revolutionize the portrayal of women amid the constraining and risk-averse structures of network broadcasting practices. In addition, her in-depth analysis of audience letters to the network provided significant insights as to how televisual representations resonated in the realm of people's lived experiences. In the end, D'Acci's study exemplified the argument that meaning can, in fact, never be guaranteed - neither in the construction of media texts nor in their reception; and it certainly cannot be read simply off of ownership structures and advertising interests. Rather, the entire circuit of production is one of constant ideological negotiation and discursive struggle in the attempt to frame representations within a specific sociohistorical context. Few scholars have replicated the breadth and rich detail of Defining Women and it is astonishing that those who criticize the absence of industrial context and "de-materialism" of cultural studies have not recognized the contribution of D'Acci's production research. Indeed, it stands as an exemplar of the value of a cultural studies perspective to our understanding of the media as cultural industries.

Outside of the Anglo-American context, Australian scholars of television and cultural studies were also beginning to move beyond the stalemate between politicaleconomy and cultural studies by engaging in what they termed "middle-range" industry-focused studies, drawing on the work of the sociologist Robert Merton (1968), whose frustration with both classical sociological theory and positivist social science led him to insist on the need for theory that "mediates between gross empiricism and grand speculative doctrines" (p. 132). John Sinclair (1999); Sinclair, Jacka, and Cunningham (1996); Tom O'Regan (1990, 1992); and Stuart Cunningham and Elizabeth Jacka (1996) have been among the most ardent proponents of industrybased research that "is situated between political economy and microsituational reception studies" (Cunningham \& Jacka, 1996, p. 22). The emphasis on the need to connect industry practices with issues of broadcasting and media policies also sets Australian scholarship apart from their American counterparts. We see this as a useful corrective to U.S. industry scholarship that often elides larger regulatory structures through an emphasis on the internal operations of particular production sites. Indeed, in the United States, media policy studies and production/industry studies have tended to develop in separate streams rather than within what would be a most productive dialog with one another. Australian research thus provides an important reminder that the state still matters in the structure of media institutions and often delimits possible room for maneuver within media institutions. Overall, our conception of critical media industry studies finds a good deal of similarity with these middle-range theorists, in particular their concerns about how political-economic structures, industrial practices, and textual meaning interact with and determine one another. However, we prefer the moniker of critical media industry studies over middle-range theory because it more precisely identifies our shared object of study and distinguishes our work from more general sociological research. Still, we consider critical media industry studies to be a form of middle-range theory. 
The past decade has marked what might be termed a "reemergence" of interest in industry-based research within UK and U.S. cultural studies. ${ }^{1}$ The publication of the circuit of culture model by du Gay et al. in 1997 provided scholars with a common speaking point from which to debate and analyze the relationships between culture and industry. This theoretical framework was notably extended in the cultural economy work of du Gay and Pryke and Hesmondhalgh in their 2002 publications. In many ways this scholarship marked a return to Hall's encoding/decoding model and more extensive consideration of the interconnections of media production and reception. It also acknowledged the centrality of production practices left unconsidered by much political economy research.

By the early 2000s, conglomeration, globalization, and digitalization were rapidly and radically restructuring the media industries. Indeed, existing and emerging research perspectives were hard-pressed to keep abreast of these changes, and substantial reconsideration of the relationships between cultural production and industrial practices in an increasingly interconnected world proved integral to contemporary media studies. Key interventions along these lines included Hesmondhalgh's (2002) emphasis on the contested nature of industrial practices when they are examined at more quotidian levels. Although the level of analysis in his work is similar to the "helicopter" heights of Gitlin and Turow, his research and that of contemporaries such as Keith Negus also incorporate assessments of the concurrent structural impediments to agency. Du Gay and Pryke's (2002) contention of the inextricability of culture and economics makes a well-known assertion, but the fact that they illustrate this argument through work that is simultaneously-and clearly-concerned with the complexity of cultural texts and audience reception practices provides a valuable force to guide subsequent scholars back toward more materialist approaches to cultural studies.

Among the most recent work contributing to critical media industry studies is a new model proposed by D'Acci (2004), the "circuit of media study," which offers a thorough discussion of the evolution from Johnson's (1986/1987) model through the circuit of culture and the debates surrounding them. Ultimately, D'Acci's circuit is more of a framework than a model in its deliberate flexibility. She streamlines the aspects of the cultural processes that appear redundant in the circuit of culture, but maintains its multidirectional connections among four sites: cultural artifact, production, reception, and sociohistoric context. Importantly for critics of cultural studies, D'Acci explicitly addresses power in terms of hegemony theory and the practice of articulation.

John Caldwell's recent book, Production Culture (2008), also offers a related intervention, although one arguably more focused within the site D'Acci distinguishes as production. Over the past decade, Caldwell has endeavored to expand the place of media industry studies in a manner that steers curiously clear of cultural studies and political economy debates and is instead concerned with intervening in the methods and theories central to the critical study of film. His recent work names cultural studies of media production as examinations of "critical industrial practices." 
Consistent with our research, Caldwell emphasizes the need to turn a critical eye on the industrial practices obscured by political economy's jet-plane view, as he focuses on artifacts such as technology user manuals, production narratives, industrial events, and institutional and procedural rituals as valuable sites of analysis for understanding how and why certain cultural forms are produced. Caldwell's methodology for these investigations - close readings of industry discourses, interviews, and ethnographic participation in industrial practices - is entirely consistent with our proposed research framework. Together these formative voices, from Williams through Caldwell, approach their studies with a fairly consistent view toward how culture works as a material process in a way that distinguishes them from others studying the intersection of culture and industry.

A number of methodological interventions have been made over the last several years, which further illustrate the distinction and type of scholarship that we argue are particular to critical media industry studies. Two books on gender and the British magazine industry published in 2003 provide excellent and differentiated models. Anna Gough-Yates (2003) and Ben Crewe (2003) explore the interconnections among sociohistorical changes and industrial factors on adjustments in new magazine titles, their content, and success. Both identify their research as characteristic of a "cultural economy" approach, explicitly citing du Gay (1997) and du Gay and Pryke (2002), and an early definition of cultural economy. Crewe delimits his use of cultural economy from other approaches by noting the following:

In looking for general, rather than abstract laws of cultural production, both political-economic and production-of-culture approaches subordinate individual intentions and influences, and interpersonal relationships and resources, to economic, social, and organizational structures. Cultural products are seen almost entirely as the outcomes of coherent - rather than complex and often conflictual - group processes, organizational "needs," market arrangements, and material forces. A cultural economic focus on the micropractices of commercial culture emphasizes the agency and creativity that occurs within, and itself reconfigures, these structural constraints and imperatives. Its concern with the cultural dimensions of commercial provision highlights the specificity of occupational languages and institutional conventions, as they develop historically and often incoherently. Change and anomaly are much better explained through such close scrutiny (pp. 20-21).

Likewise, Gough-Yates notes that she adopts "an analytical framework known in cultural studies as 'cultural economy,' and views 'economic' activities as profoundly 'cultural phenomena"' in explicit citation of du Gay and Pryke's sense of term (p. 5). She acknowledges that "one consequence of this approach is that I view the processes of production and systems of organization of the magazine and advertising industries as discursive. These industries carry meanings about how such sites should be thought about and responded to by others" (p. 5). Both authors use these frameworks to provide rich accounts of the complicated industrial and cultural forces that allowed 
for the emergence of "new women" magazines, in the case of Gough-Yates' study, and the complexity of the "new lad" and general explosion in the men's magazine market by Crewe.

We have no quarrel with these authors' work, and find it to very precisely embody what we address as critical media industry studies. Both books were published just a year after du Gay and Pryke's collection appeared in print and before the explosion of "culturalization of the economy" research that has since become closely identified with the cultural economy terminology and moved it away from perspectives first valuable for critical media industry studies. It remains unclear whether or not cultural economy is as explicitly and consistently connected with cultural studies as GoughYates asserts it to be, particularly as cultural studies has long posited a dialectical relationship between culture and economics (in other words, the economic has always been cultural and vice versa). In addition, little conversation exists among this work and Caldwell's call for the study of critical industrial practices. What we find troubling is the way in which like-minded work such as that reviewed here is not connecting or finding itself in conversation-indeed the breadth of scope offered here largely results from the combined efforts of three coauthors who have been sharing finds and potential influences for several years. Perhaps because of the lack of a common language with which to identify and name an approach, the increased attention to media industries has not yet generated the momentum that may lead to vital contributions emerging from a dialog of shared theories, methods, and visions.

\section{Critical media industry studies: Theories and methods}

Key features of the critical media industry studies framework include a "helicopter" level view of industry operations, a focus on agency within industry operations, a Gramscian theory of power that does not lead to complete domination, and a view of society and culture grounded in structuration and articulation. Consistent with the work of Hesmondhalgh (2002), who theorizes media entities as cultural industries, we find it important to centralize the term "industry." The manner in which this term invokes the work of the Frankfurt School and its often-contested place within cultural studies is something we also wish to acknowledge. We share Hesmondhalgh's opinion that the work of Bernard Miège (1989) improves on the work of critical theorists such as Adorno and Horkheimer (1972) by attending to the contradictions within the culture-producing industries; the tensions between consumption and production; and importantly, the significance of sociohistorical context at all points of analysis (2002, pp. 33-35). Our endeavor, however, to revive a past moment in materialist cultural studies proceeds from the premise that there are certain theories and methods within this paradigm, which are particularly well-suited to understanding how the media and related industries operate as both cultural and culture-producing institutions. In fact, Hesmondhalgh's (2002, pp. 39-41) own acknowledgment of some of the strengths of cultural studies are precisely those that exemplify our argument; namely, the need to take ordinary culture seriously; an 
understanding of the complexity of defining "culture;" the emphasis on vital questions of authority-who speaks and under what conditions; and the attention given to issues of discourse, subjectivity, and textuality as important components of "culture."

Following the arguments of de Certeau (1984), we envision and propose critical media industry studies through grounded institutional case studies that examine the relationships between strategies (here read as the larger economic goals and logics of large-scale cultural industries) and tactics (the ways in which cultural workers seek to negotiate, and at times perhaps subvert, the constraints imposed by institutional interests to their own purposes). Much cultural studies scholarship in the areas of textual analysis and audience reception has been critiqued for its propensity to reduce discourse analysis into a form of word play in which texts are deconstructed with the intent to read "society" writ large off of representational constructions. Our intent here is to recuperate the analysis of discourse, in the Foucauldian sense, as the formation of knowledge (and thus power). This entails analyzing how institutions organize ways of knowing into seemingly irrefutable logics of how systems should operate, thereby bringing to the forefront the material consequences of industrial "common-sense" in a manner correspondent with Gramsci's analysis of power relations in liberal-democratic societies. Herein, power and resistance are mutually constitutive and we see this as a potentially productive window into the ways that cultural workers maintain some degree of agency within the larger constraints imposed by the structural imperatives of the media industries, their owners, and regulators. Tinic's (2005) fieldwork within the Vancouver, British Columbia runaway television and film locations industry-Hollywood North - is an illustrative case. In contrast to macrolevel arguments that the locations industry operated as an American cultural branch plant, Tinic found that many Canadian producers worked on service productions to develop the necessary networks and resources to develop their own domestic projects in a process of resistance to federal funding and policy institutions that had long marginalized regional television production within centralized discourses of what constituted "nationally" representative programming.

Thus, the way in which institutional discourses are internalized and acted upon by cultural workers is an important missing link between political economy's concentration on larger economic structural forces and much of cultural studies' analyses of end products such as media texts and audience interpretations. It is within the ambiguity and complexity of the processes that lead from story ideas to their constituent production decisions, as contextualized within network goals and regulatory environments, that we can begin to understand the material "products" that have come to engage media studies scholars. By reinforcing the centrality of examining and observing the structural discourses and conditions within which cultural agents operate, we echo du Gay and Pryke's (2002) assertion that:

[T] echniques of "economic management" do not come ready-made. They have to be invented, stabilized, refined and reproduced; they have to be disseminated and implanted in practices of various kinds in a range of different locales (p. 8). 
Giddens' (1991) conceptualization of structuration provides us with a theory of institutional power dynamics that is particularly well-suited to addressing such microlevel practices and their connection to larger industry goals and discourses. In direct opposition to functionalist theories of society, Giddens argued that the traditional analytical divide between structure and agency was based on a faulty premise that negated the dialectical relationship between the two sites of determination. Structuration, conversely, emphasizes the means by which the rules and discourses of social structures are internalized by social actors. The articulation of these value systems within social practice becomes a central locus of analysis wherein the negotiation of, resistance to, and reproduction of structural constraints illustrates the potential for social change and/or continuity in material form. Structuration theory provides media industry studies with a conceptualization of power capable of operating at different levels simultaneously — not only in the negotiation of roles, policies, industry goals, and production practices but also in the broader terrain of ownership interests. Significantly, power does not only operate on multiple levels, but it is not so pervasive as to allow for complete domination. The operation of power is constantly involved in assertion and negotiation and, most importantly, is never permanently achieved.

Critical media industry studies is consequently unlikely to propose that an entity or individual (the FCC or Rupert Murdoch) is capable of exerting consistent and uncontested control over the means of cultural production, regardless of disproportionate access to economic and institutional power. Indeed, this form of economic overdetermination at the macrolevel of analysis has been one of the primary critiques levied against American political-economic media research. The emphasis on ownership and market logics elides the complex workings within the media industries where cultural workers negotiate every facet of the production process in ways that cannot be easily predicted by or read off from the interests of those who control the allocative resources of the industries. It is in this regard that we believe the theories and methods of cultural studies are well positioned to provide an intervention into the analysis of media industries.

Similar to political economy, cultural studies draws on a rich history of critical social and political theories. However, one distinguishing trait of cultural studies scholarship is the continued emphasis on the quotidian practices that form the integral building blocks of cultures. Cultural studies begins from the premise that culture is both anthropological and expressive. In other words, a critical media industry studies approach would explore the corporate dimensions of the media as a cultural system with its own tacit and explicit, yet contested, rules, while connecting these to the actual production and operation of textual forms. As such, the contribution of cultural studies to institutional analysis is one that directs our attention away from strictly economic models and compels us to explore the tacit assumptions and cultural constructions that inform the everyday practices of cultural producers and their subsequent translation into the popular texts that contribute to larger sociocultural dialog. Here the emphasis is on the myriad ways 
in which specific discourses are constructed and articulated at various institutional sites including policy, regulation, production practices, distribution, and marketing and how such discourses are incorporated or resisted in the practices of cultural workers. In accordance with Jensen's (1984) appeal to understand the production process as a cultural and symbolic activity, it is essential that we consider "what is being negotiated ... what eventually becomes public from what is suggested and how that is determined by people's beliefs about business, materials, audiences, the times" (p. 114).

Our intent is not to lay claim to the assertion that the media are both economic and cultural institutions. Indeed, over a decade ago, media political economist Eileen Meehan (1994) underlined the importance of studying television as a "contradictory" institution in that it is both a site of artistic and social expression as well as a business concerned with the maximization of markets and profits. Rather, our objective is to provide a research framework that furthers understandings of how these contradictions work within actual practice; and, more importantly, what implications these practices - and the texts they generate-hold in terms of larger social and cultural processes of representation and power.

As the foregoing discussion indicates, ours is as much a theoretical and methodological reclamation project as it is a proposed new direction forward. Consequently, we do not wish to conclude with a prescriptive or exclusive list of sanctioned theories and methods that delimit the parameters of critical media industry studies. Indeed, an ecumenical perspective is integral to understanding the contemporary moment of institutional change. In addition to the theories and scholars we have already mentioned, we can easily envision a range of critical approaches that could be incorporated within this model. For example, Stabile's (1995) call for Bourdieu-inflected work that would examine the competing "rules of the game" in the "field" of media institutions exemplifies the form of case studies we envision. So, too, would Callon and Latour's (1981) actor-network research that focuses on the ways in which the routinization of organizational work is "black-boxed" in a manner that elides the specific contributions and contestations of various agents in the generation of common-sense assumptions about the cultural production process. That said, we expect that research under the auspices of critical media industry studies would share a fundamental concern with key issues and tenets - namely, the need for empirical (not empiricist) research into the media industries with an eye towards the struggle over ideological hegemony in the production of popular culture, in particular.

With regard to the first point, it is important to reiterate our concern with the material impact of the media industries within the cultural, social, and political spheres. The media are concrete entities with specific interests and, therefore, abstract philosophies or high theory does not bring us any closer to understanding their centrality as meaning-making institutions. This is not to minimize the significance of theory building, but rather to stress the imperative of case study methods that shed light on the ways in which members of the media industries define the conventions of production and distribution based on their assumptions of the prevailing cultural 
values and issues of the time. Hence our earlier emphasis on theoretically informed ethnographies and textual and discursive analysis of industry trade publications and regulatory debates as a few of the many potential research sites appropriate within a critical media industries approach. As to the second point, the history of industry studies in media and communication studies has tended to focus on the organization of news media production. We see the dearth of attention to popular culture (or entertainment) production as a gap that must be filled. News and entertainment are organizationally distinct from one another. For example, news outlets do not attempt to capture popular trends and reconstruct them within specific fictional narrative and genre conventions with the goal of attracting preferred audiences for advertising interests. Instead, news programming, while still predominantly concerned with audiences and advertisers, privileges the "reality function" of its rules and conventions and therein attributes a higher cultural value to this type of media production. Conglomerates and their owners and patrons reinforce this perspective and are highly sensitive to the treatment of news coverage as a component of their business holdings. The designation of entertainment as escapist, low culture means that popular culture has not been taken as seriously as a political force within these sectors. This division has replicated itself in the breech between cultural studies and political economy analyses of the media industries. Consequently, the critical media industry studies approach we are describing is one that accords due significance to the political, economic, and social dimensions of popular culture production. What both corporate owners and political economists see as "mass culture" is a crucial site of struggle and resistance for marginalized groups at both the local and global levels. Ignoring the logic of representational practices in entertainment production works to reinforce the relative invisibility or misrepresentation of those who often have the least power in the public sphere.

Generating momentum for a diverse range of multisite research endeavors within a critical media industry studies approach is vital to furthering our understanding of the current moment of uncertainty that defines today's media environment. Media conglomerates and professionals are attempting to redefine their conventional practices - or industrial common sense - in an era of technological convergence, DIY media projects, and the acceleration of global production and distribution strategies. As new content windows proliferate and audiences continue to fragment (locally and globally), members of the industry are negotiating ways to simultaneously apply old rules to a new game while exploiting the potential to revolutionize both content and economic gain. The type of research we are advocating is integral to analyzing an industry in flux and the struggles among competing social actors and institutions to stabilize new discourses to their own specific interests and advantages.

\section{Notes}

1 D'Acci (2004) provides an excellent historical account of the ways in which media industry research, from a cultural studies perspective, was marginalized in the wake of the 
publication of key texts that introduced the paradigm to new disciplines-in particular English departments in the United States. As a result, by the late 1980s, television studies moved decidedly toward textual analysis and, in subsequent years, toward theories of readership or reception. Although, as D'Acci underlines, media industry studies appeared to be sidelined in favor of more literary approaches, there were still television studies scholars attempting to bring production research back into the fold.

\section{References}

Adorno, T., \& Horkheimer, M. (1972). Dialectic of enlightenment. New York: Herder and Herder.

Anderson, C. (1994). Hollywood TV: The studio system in the fifties. Austin: University of Texas Press.

Bagdikian, B. (2004). The new media monopoly. Boston: Beacon Press.

Boddy, W. (1990). Fifties television: The industry and its critics. Urbana: University of Illinois Press.

Caldwell, J. T. (2008). Production culture: Industrial reflexivity and critical practice in film and television. Durham: Duke University Press.

Callon, M., \& Latour, B. (1981). Unscrewing the big leviathan: How actors macro-structure reality and how sociologists help them do so. In K. Knorr-Cetina \& A. Cicourel (Eds.), Advances in social theory and methodology (pp. 277-303). London: Routledge \& Kegan Paul.

Cunningham, S., \& Jacka, E. (1996). Australian television and international mediascapes. Cambridge: Cambridge University Press.

Crewe, B. (2003). Representing men: Cultural production and producers in the men's magazine market. Oxford: Berg.

Croteau, D., \& Hoynes, W. (2006). The business of media: Corporate media and the public interest (2nd ed.). Thousand Oaks: Pine Forge Press.

Curtin, M. (1995). Redeeming the wasteland: Television documentary and cold war politics. New Brunswick: Rutgers University Press.

D'Acci, J. (2004). Cultural studies, television studies, and the crisis in the humanities. In L. Spigel \& J. Olsson (Eds.), Television after TV: Essays on a medium in transition (pp. 418-446). Durham: Duke University Press.

D'Acci, J. (1994). Defining women: The case of Cagney and Lacey. Chapel Hill: University of North Carolina Press.

de Certeau, M. (1984). The practice of everyday life. Berkeley: University of California Press.

du Gay, P., Hall, S., Janes, L., \& Mackay, H. (1997). Doing cultural studies: The story of the Sony Walkman. London: Sage.

du Gay, P. (Ed.). (1997). Production of culture/cultures of production. London: Sage.

du Gay, P., \& Pryke, M. (2002). Cultural economy: An introduction. In P. du Gay \& M. Pryke (Eds.), Cultural economy: Cultural analysis and commercial life (pp. 1-20). London: Sage.

Foucault, M. (1979). Discipline and punish: The birth of the prison (A. Sheridan, Trans.). New York: Vintage Books.

Garnham, N. (2005). A personal intellectual memoir. Media, Culture \& Society, 27(4), 469-93.

Giddens, A. (1991). The consequences of modernity. Palo Alto: Stanford University Press.

Gitlin, T. (1983). Inside prime time New York: Pantheon Books. 
Gramsci, A. (1971). Selections from the prison notebooks of Antonio Gramsci. (Q. Hoare \& G. Nowell Smith, Trans./Eds.). New York: International Publishers.

Gough-Yates, A. (2003). Understanding women's magazines: Publishing, markets and readerships. London: Routledge.

Hall, S. (1983). Cultural studies: Two paradigms. In T. Bennett, G. Martin, et al. (Eds.), Culture, ideology and social process (pp. 19-37). London: Open University Press.

Hartley, J. (2005). Creative industries. In J. Hartley (Ed.), Creative industries (pp. 1-41). Malden, MA: Blackwell.

Havens, T. (2006). Global television marketplace. London: BFI.

Herman, E., \& McChesney, R. (1997). The global media: The new missionaries of global capitalism. London and Washington: Cassell.

Hesmondhalgh, D. (2006). Bourdieu, the media and cultural production. Media, Culture and Society, 28(2), 211-32.

Hesmondhalgh, D. (2002). The cultural industries. London: Sage.

Jensen, J. (1984). An interpretive approach to cultural production. In W. Roland (Ed.), Interpreting television: Current research perspectives (pp. 98-117). Beverly Hills: Sage.

Johnson, R. (1986/1987). What is cultural studies anyway? Social Text, 16, 38-80.

Lotz, A. D. (2007). How to spend $\$ 9.3$ billion in three days: Examining the upfront buying process in the production of U.S. television culture. Media, Culture \& Society, 29(4), 549-567.

Meehan, E. (1994). Conceptualizing culture as commodity: The problem of television. In H. Newcomb (Ed.), Television: The critical view (pp. 563-572). New York: Oxford University Press.

Merton, R. (1968). Social theory and social structure. New York: Free Press.

Miege, B. (1989). The capitalization of cultural production. New York: International General.

Murdock, G., \& Golding, P. (2005). Culture, communications and political economy. In J. Curran \& M. Gurevitch (Eds.), Mass media and society, 4th ed. (pp. 60-83). London: Arnold.

O'Regan, T. (1992). The international, the regional, and the local: Hollywood's new and declining audiences. In E. Jacka (Ed.), Continental shift: Globalization and culture (pp. 75-98). Double Bay, N.S.W.: Local Consumption.

O’Regan, T. (1990). Too popular by far: On Hollywood's international popularity. Continuum: The Australian Journal of Media and Culture, 5(2), 302-351. http://wwwmcc.murdoch.edu.au/ReadingRoom/5.2/O'Regan.html (downloaded 24 September 2004).

Owen, B., \& S. Wildman (1992). Video economics. Cambridge and London: Harvard University Press.

Peterson, R. A. (1982). Five constraints on the production of culture: Law, technology, market, organizational structure and occupational careers. Journal of Popular Culture, 16(2), 143-152.

Peterson, R. A., \& Anand, N. (2004). The production of culture perspective. Annual Review of Sociology, 30, 311-344.

Schiller, H. (1989). Culture, Inc.: The corporate takeover of public expression. New York: Oxford University Press.

Sinclair, J. (1999). Latin American television: A global view. New York and Oxford: Oxford University Press.

Sinclair, J., Jacka, E., \& Cunningham, S. (Eds.). (1996). New patterns in global television: Peripheral vision. Oxford and New York: Oxford University Press. 
Smythe, D. (1981). Dependency road: Communications, capitalism, and consciousness, and Canada. Norwood, NJ: Ablex Pub.

Stabile, C. (1995). Resistance, recuperation, and reflexivity: The limits of a paradigm. Critical Studies in Mass Communication, 12, 403-422.

Stevenson, N. (2002). Understanding media cultures: Social theory and mass communication. London: Sage.

Tinic, S. (2005). On location: Canada's television industry in a global market. Toronto: University of Toronto Press.

Turow, J. (1997). Media systems in society: Understanding industries, strategies and power (2nd ed.). New York: Longman.

Turow, J. (1990). Media industries, media consequences: Rethinking mass communication. Communication Yearbook, 13, 478-501.

Turow, J. (1981). Unconventional programs on commercial television: An organizational perspective. In C. Whitney \& J. Ettema (Eds.), Individuals in mass media organizations (pp. 107-130). Beverly Hills: Sage Publications.

Waterman, D. (2005). Hollywood's road to riches. Cambridge, MA: Harvard University Press.

Williams, R. (1958/1983). Culture and society, 1780-1950. New York: Columbia University Press. 